\title{
IMPLICAÇÕES DA POLUIÇÃO LUMINOSA NAS ÁREAS DAS CIÊNCIAS E DA SOCIEDADE
}

\author{
IMPACTS OF LIGHT POLLUTION IN SCIENCE AND SOCIETY
}

\author{
Jose Laercio Araujo ${ }^{1}$ \\ Enos Picazzio ${ }^{2}$
}

RESUMO: $O$ artigo tem por objetivo mostrar que a poluição luminosa, não conhecida no Brasil afeta o ecossistema atingindo a saúde humana, fauna e flora. Atinge a segurança, no ir e vir das pessoas. Provoca danos à economia, por perdas advindas de projetos mal elaborados do uso de energia. Prejudica a educação, na área da astronomia. As outras poluições possuem legislação protegendo o meio ambiente de seus efeitos. Porém, a PL no Brasil não tem legislação. Todavia, o Chile, Itália, França, Portugal, Estados Unidos, Checoslováquia, Iugoslávia, controlam a poluição luminosa com legislação. Por este estudo, propomos três caminhos para o controle dos danos causados pela PL, área da educação, utilizando-se do processo de mudança, proposta de projeto de lei, e a criação de um portal interativo com professores e alunos, abarcando informações conscientizantes à sociedade a respeito dos danos provocados pela PL.

\footnotetext{
1 Doutorado em Direito Constitucional pela PUC/SP.e Mestre em Ciências, com ênfase em Astronomia pela USP, Mestre em Direito Político e Econômico, com ênfase em Direito Penal pelo Mackenzie. Pós graduação em Psicologia da Educação e Psicologia do desenvolvimento da aprendizagem, pela UPPRIMORE SISTEMA EDUCACIONAL LTDA. Especialista em Direito Processual Penal pelas FMU, Direito da Propriedade Intelectual pela O.M.P.I, Gestão de Meio Ambiente pela IBEAM, Possui graduação em Ciências com ênfase em Matemática e Física. É Bacharel em Direito pela UNG, Tem se dedicado aos estudos de Astronomia e astrofísica, por meio de participação em diversos cursos de Extensão Universitária no IAG/USP, no Observatório Nacional e na Escola Municipal de Astrofísica de São Paulo. Bacharel, Mestre e Doutor em Teologia pela FATESP. Concluiu no Instituto de Física da USP os cursos em nível de extensão Universitária: Introdução à Física de partículas, Óptica Teoria e Experimentos, Massa - O conceito de Newton a Higs, Ferrofluidos - Propriedades e aplicações, Experimentos para o ensino de Astronomia, Introdução à Astronomia e Astrofísica, Magnetismo da terra, Astronomia - Uma visão geral. Atuou como Monitor no ensino de astronomia no programa atendimento ao público do IAG/USP. Cursando, em nível de Pós graduação lato senso, "Inovação em Tecnologias Educacionais" e MBA em Gestão Ambiental junto à UPPRIMORE SISTEMA EDUCACIONAL LTDA - MG, Cursando Pós lato sensu em Neuropsicologia clínica e Comportamental, pela Faculdade Batista de MG, Psicologia Clínica e Comportamental e Gestão Ambiental junto ao CEPED. Astrônomo Amador pelo C.A.S.P. Autor do livro "Intimidade, Vida Privada e Direito Penal", publicou artigo sob o tema: "O Universo seria cíclico? Como ficariam as teorias do Big Bang, do Evolucionismo e o Creacionismo bíblico". E-mail: araujoadv@alumni.usp.br

2 Pós-doutorado pelo Observatório de Paris-Meudon (1994). Professor Doutor do Instituto de Astronomia, Geofísica e Ciências Atmosféricas da USP. Desenvolve pesquisa em "Astrofísica do Sistema Solar", com ênfase em Cometas. Tem experiência em desenvolvimento de instrumentação solar e astronômica em infravermelho. É editor de livro, autor de capítulos em livros, autor de artigos em revistas e de material didático disponibilizado em sítios, dedicados ao Ensino e à Divulgação. É coordenador acadêmico do curso semipresencial de Licenciatura em Ciência da USP. Membro titular da Comissão Coordenadora de Programa (CCP) do Mestrado Profissional no Ensino de Astronomia (MPEA), representante titular do MPEA na Comissão de Pós-Graduação do IAG/USP e orientador no MPEA. Licenciatura e Bacharelado em Física pela Universidade Presbiteriana Mackenzie (1972), Mestrado em Astronomia pela Universidade de São Paulo (1977), Doutorado em Astronomia pela Universidade de São Paulo. E-mail: epicazzio@iag.usp.br
} 
Palavras-chave: Poluição luminosa. Luz. Astronomia. Impacto ambiental e legislação.

ABSTRACT: The article aims to show that light pollution, not known in Brazil affects the ecosystem affecting human health, fauna and flora. It reaches safety, in the coming and going of people. It causes damage to the economy, due to losses arising from poorly designed energy use projects. It harms education in the area of astronomy. The other pollutions have legislation protecting the environment from its effects. However, PL in Brazil has no legislation. However, Chile, Italy, France, Portugal, the United States, Czechoslovakia, Yugoslavia, control light pollution with legislation. For this study, we propose three ways to control the damages caused by the PL, the education area, using the process of change, proposed bill, and the creation of an interactive portal with teachers and students, covering awarenessraising information to the society regarding the damages caused by the PL.

Keywords: Light pollution. Light. Astronomy. Environmental impact and legislation.

\section{INTRODUÇÃO}

A natureza como um todo, suporta nos dias de hoje, muitos tipos de poluição, os quais trazem diversos prejuízos ao meio ambiente e, no Brasil não é diferente. As poluições mais conhecidas e estudadas são: poluição do ar, da água, do solo, a sonora, visual e poluição nuclear ou radioativa. Todos esses tipos de poluição já são objetos de legislação. Mas será que além desses tipos de poluição mencionados pode existir outro tipo ainda não reconhecido e não regulamentado? Com certeza sim. Por este trabalho de pesquisa, identificamos um tipo de poluição diferente e muito séria para o meio ambiente como um todo, ou seja, a poluição luminosa. Mas, o que vem a ser poluição luminosa? Pois bem, temos muitas dúvidas em relação ao tema em evidência, mas, podemos iniciar por defini-la como sendo: todo excesso de luz artificial colocada de forma errônea, com origem em projetos mal elaborados, no meio ambiente, de forma a causar ou produzir efeitos negativos ao ecossistema, principalmente nos seguintes segmentos da sociedade em geral: a) economia, no que se refere ao consumo e desperdício de energia elétrica; b) área da saúde, nos seres humanos, fauna e flora; c) área da segurança, no ir e vir das pessoas, causando a falsa impressão de que, com mais iluminação estamos melhores protegidos e d) área da 
educação, em sua área da astronomia, nos estudos de objetos celeste, impedindo suas visualizações. A poluição luminosa está ligada a alguns fatores, tais como: crescimento populacional e problemas técnicos na elaboração de projetos de iluminação. Em 28/04/202I a população do globo terrestre atingiu 7,88 bilhões de habitantes ${ }^{3}$, que no Brasil pode ser a principal razão do aumento do consumo de energia elétrica, e ainda segundo a mesma fonte, em 2050 estima-se que essa população passe a ser de 9,9 bilhões de pessoas. No Brasil, em abril de 2021 a população era de 214,4 milhões de pessoas ${ }^{4}$, que consumiram no ano de 2020, 474.221.492 $\mathrm{MWh}$, segundo a $\mathrm{EPE}^{5}$, deste número destacamos que o consumo de energia elétrica na área pública foi de $77.773 .662 \mathrm{MWh}$, nos 5.570 municípios. A relação número de pessoas versus consumo, principalmente na área pública e, no que tange aos projetos mal elaborados colocados no meio ambiente provocam a poluição luminosa ao ecossistema, afetando as áreas já acima mencionadas.

\section{DA CONCEITUAÇÃO GERAL DE POLUIÇÃO}

Mas, antes de adentrarmos ao entendimento do foco deste artigo, que é poluição luminosa e seus malefícios, vamos entender o que vem a ser, primeiramente, poluição ambiental. Deste modo, podemos dizer que: poluição $a_{\text {ambiental }}^{6}$ "é a mudança indesejada nas características físicas, químicas e biológicas de determinado ambiente. Esta alteração das condições normais do local pode causar prejuizos à saúde, à sobrevivência, ou às atividades dos seres humanos e outras espécies, além da deterioração de outros materiais". Segundo Valle (2004), a poluição ambiental pode ser definida como toda ação ou omissão do homem que, pela descarga de material ou energia atuando sobre as águas, o solo, o ar, causa um desequilíbrio nocivo ao meio ambiente, seja ele de curto ou longo prazo. Pois bem, ultrapassados esses conceitos

\footnotetext{
3 https://countrymeters.info/pt (acesso em 28/04/21 - às 17:05:04).

4 https://countrymeters.info/pt (acesso em 28/04/202I).

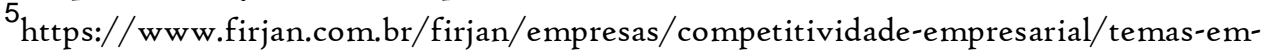
destaque/energiaeletrica/custo/default-7.htm (acesso em 28/04/2021)

${ }^{6}$ http://unifei-poluicao.blogspot.com.br/2008/II/o-que-poluio.html.(acesso em 28/o4/202I).
} 
podemos afirmar que a poluição luminosa pode ser entendida como um fator nocivo ao meio ambiente, advindo do excesso de luz artificial disponibilizado por projetos mal elaborados e pode ser dividida em tipos distintos de modalidades, pelos efeitos danosos que provocam ao meio ambiente, assim poderemos ter, segundo, Mizon (2002 - 2012), a poluição luminosa pode ser classificada em três modalidades, denominadas da seguinte forma: brilho do céu (sky glow), luz ofuscante (glare) e luz intrusa (light trespass). A British Astronomical Association (2009) adota a mesma classificação, porém com pequena diferença de interpretação: brilho do céu (sky glow), luz ofuscante (glare) e luz intrusa (light trespass) agora entendida como luz incômoda ao invés de intrusa. Todavia, no parecer de The Royal Commissionon Environment Pollution - Artificial Light in the Environment (2009), existem apenas dois tipos de luz poluidora: o brilho que ilumina e o brilho que obscurece. Estes dois tipos produzem as modalidades de poluição luminosa, podendo assumir cinco formas distintas, a saber: brilho (glare), luz invasora ou transgressora (light trespass), luz desordenada (light clutter), luz esbanjada (light profligacy) e brilho do céu (sky glow). É nossa opinião, que desta classificação se pode concluir que os tipos que iluminam são o brilho do céu (sky glow), a luz desordenada (light clutter), luz embajada (light profligacy). Por sua vez, a luz transgressora (light trespass) produz os dois efeitos: ilumina para quem se encontra atrás do ponto de iluminação e obscurece para quem está à frente dele. E por último o brilho (glare) que obscurece.

Nesta mesma linha de pensamento Chui (2009) entende que a poluição luminosa assume cinco formas seguintes: brilho (glare), luz transgressora (light trespass), luz desordenada (light clutter), luz esbanjada (light profligacy) e brilho do céu (sky glow). Independentemente das sutilezas entre elas, nós acataremos estas definições como técnicas e discutiremos como cada espécie atua no meio ambiente, atingindo os direitos humanos, as vidas animal e vegetal, a economia das cidades, a segurança das pessoas e a educação, sobretudo no que concerne à área da Astronomia. A figurar nos mostra como se caracteriza a poluição luminosa. 


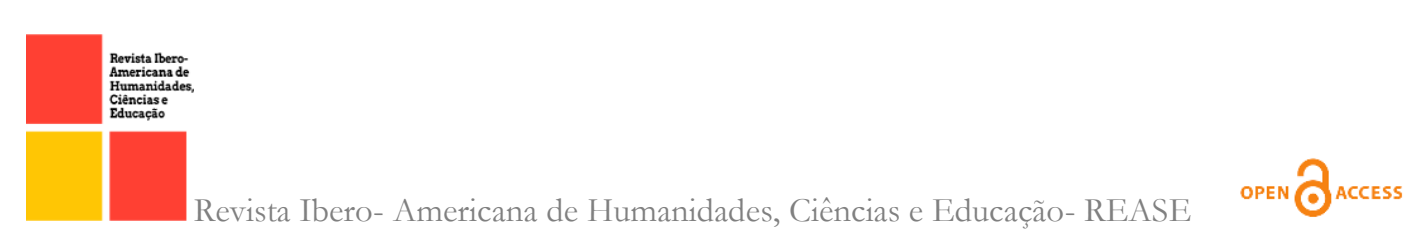

Figura I - Poluição luminosa.

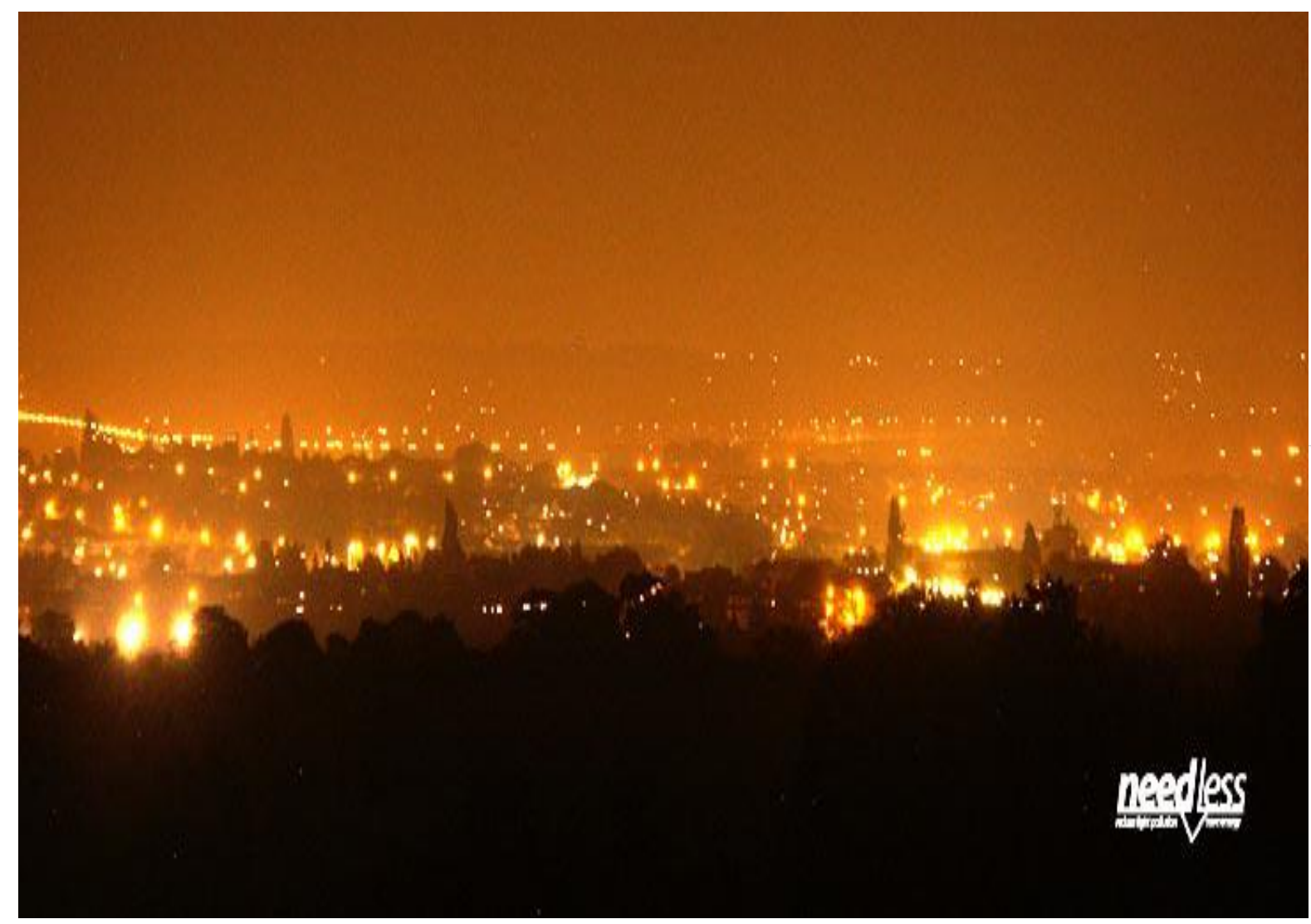

Fonte: www.need-less.org.uk. (Acesso 20/12/2016).

\section{A QUEM ATINGE OS DANOS DA POLUIÇÃO LUMINOSA?}

A poluição luminosa provoca danos ao ecossistema e atinge as seguintes áreas das ciências e da sociedade de um modo em geral: saúde dos seres humanos, a fauna, a flora, a segurança, a economia e a educação em sua área de astronomia. O tempo de exposição à poluição luminosa a que fica os seres humanos faz com que estes tenham deficiência na formação do hormônio, denominado melatonina e a partir daí adquiram determinados comportamentos inadequados, tais como: perda do sono, nervosismo exagerado, envelhecimento precoce, não transformação de cartilagem em osso; no caso de criança e uma grande possibilidade de adquirirem câncer, e no caso das mulheres câncer de mama. A figura 2 a seguir pode nos ilustrar bem essa situação. 
Figura 2

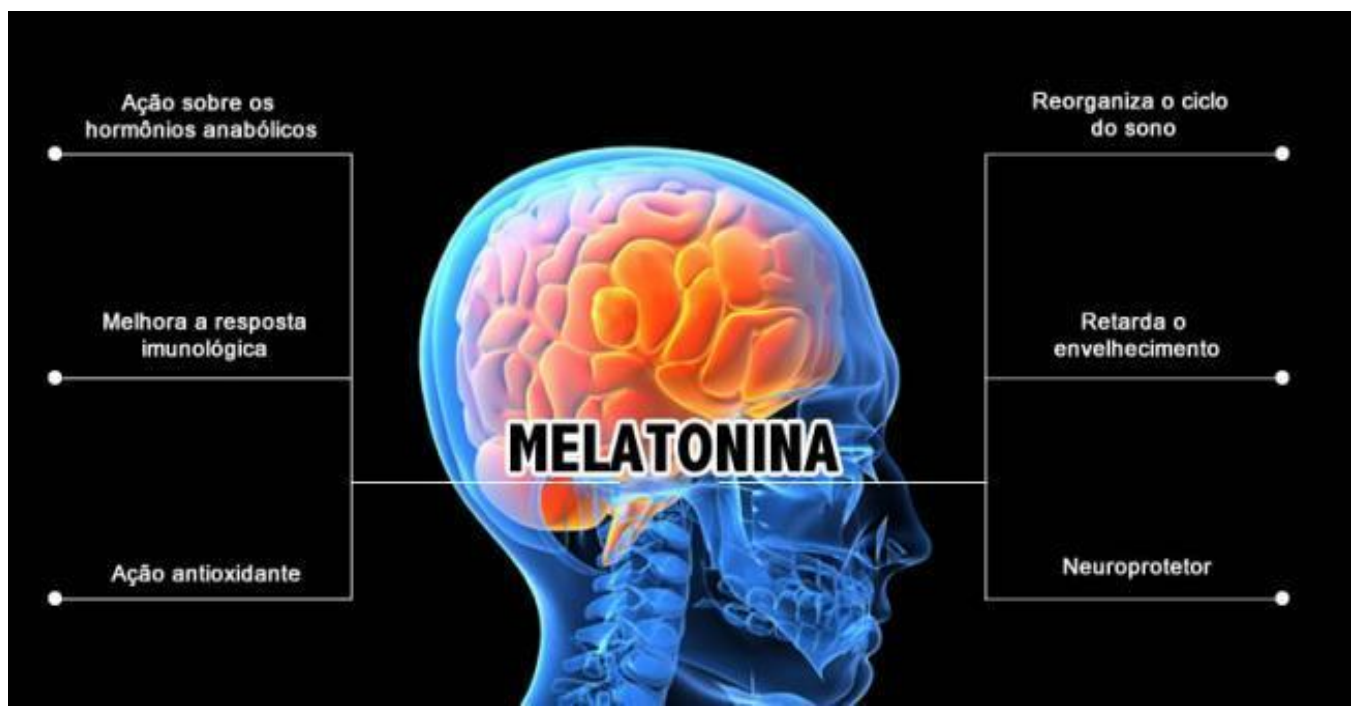

Fonte:https://www.conexaosorriso.com.br/arquivos/noticias/9593/6r6bdobco4loa382fizaf $780 b_{2} b_{45} 8 \mathrm{cf}$ .jpg (acesso 18/10/2018).

Importante salientar que a formação da melatonina ocorre pela relação dos olhos com glândula pineal, no cérebro humano, esta só ocorre no escuro e tem seu início por volta de $\mathrm{I} 8$ horas, quando os olhos informam ao cérebro o desaparecimento da luz do sol, pico máximo por volta das 2 horas da madrugada, terminando às 6 horas, horário em que os olhos informam ao cérebro o início da claridade natural. Conforme nos ilustra a figura 3 .

\section{Figura 3}

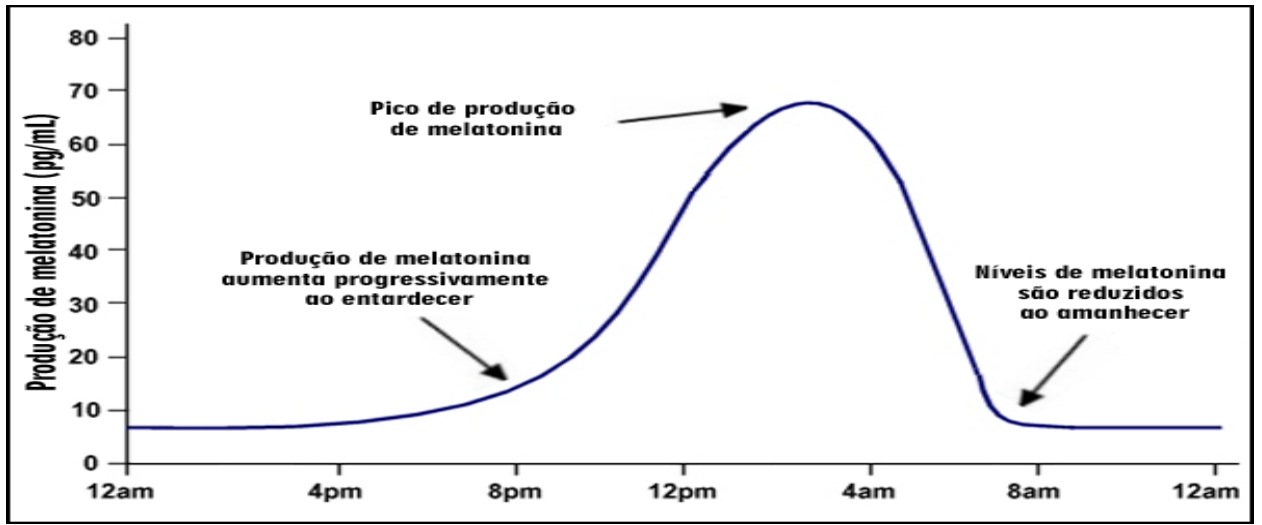

Fonte: https://www.biomedicinabrasil.com/2018/o3/as-outras-funcoes-da-melatonina.html (acesso 18/10/2018). 
$\mathrm{Na}$ fauna, a luz artificial excessiva é capaz de provocar ou atingir diversos animais não permitindo a sua procriação e manutenção de certas espécies, pela falta de acasalamento, tais como: vaga-lumes, mariposas, tartarugas e outras espécies. No caso dos vaga-lumes, eles se comunicam por códigos bioluminescentes e a poluição luminosa impede o entendimento desses códigos por parte das fêmeas da espécie e assim, não acasalam. Na flora afeta a fotossíntese, prejudicando a transformação de gás carbônico em oxigênio, mas o processo é mais complexo como nos mostra a figura 4 abaixo:

Figura 4

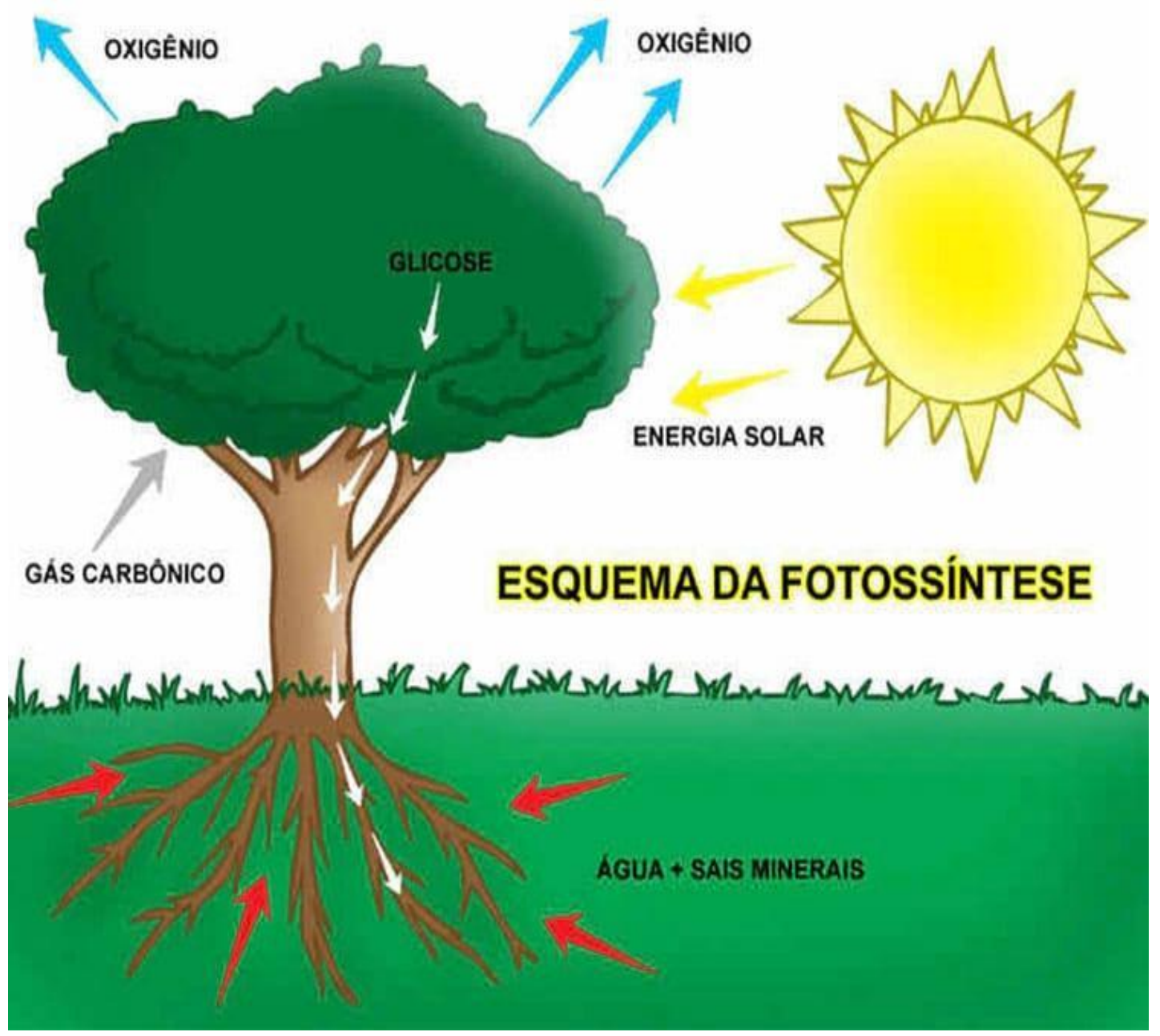

Fonte: https://www.oficinadanet.com.br/imagens/post/13727/fotossintese.jpg (acesso 18/10/2018) 
$\mathrm{Na}$ área da segurança, e no que tange ao ir e vir das pessoas no seu dia-a-dia, todos imaginam que, com uma grande quantidade de luz faz com que nos sentimos mais seguros. É um sentimento errôneo, pois a luz às vezes, voltada em nossa direção faz com que nossas visões fiquem ofuscadas e não nos permite enxergar corretamente um meliante por trás da fonte que ilumina e nos coloca em perigo iminente, como nos ilustra a figura 5 e 6.

\section{Figuras 5 e 6}

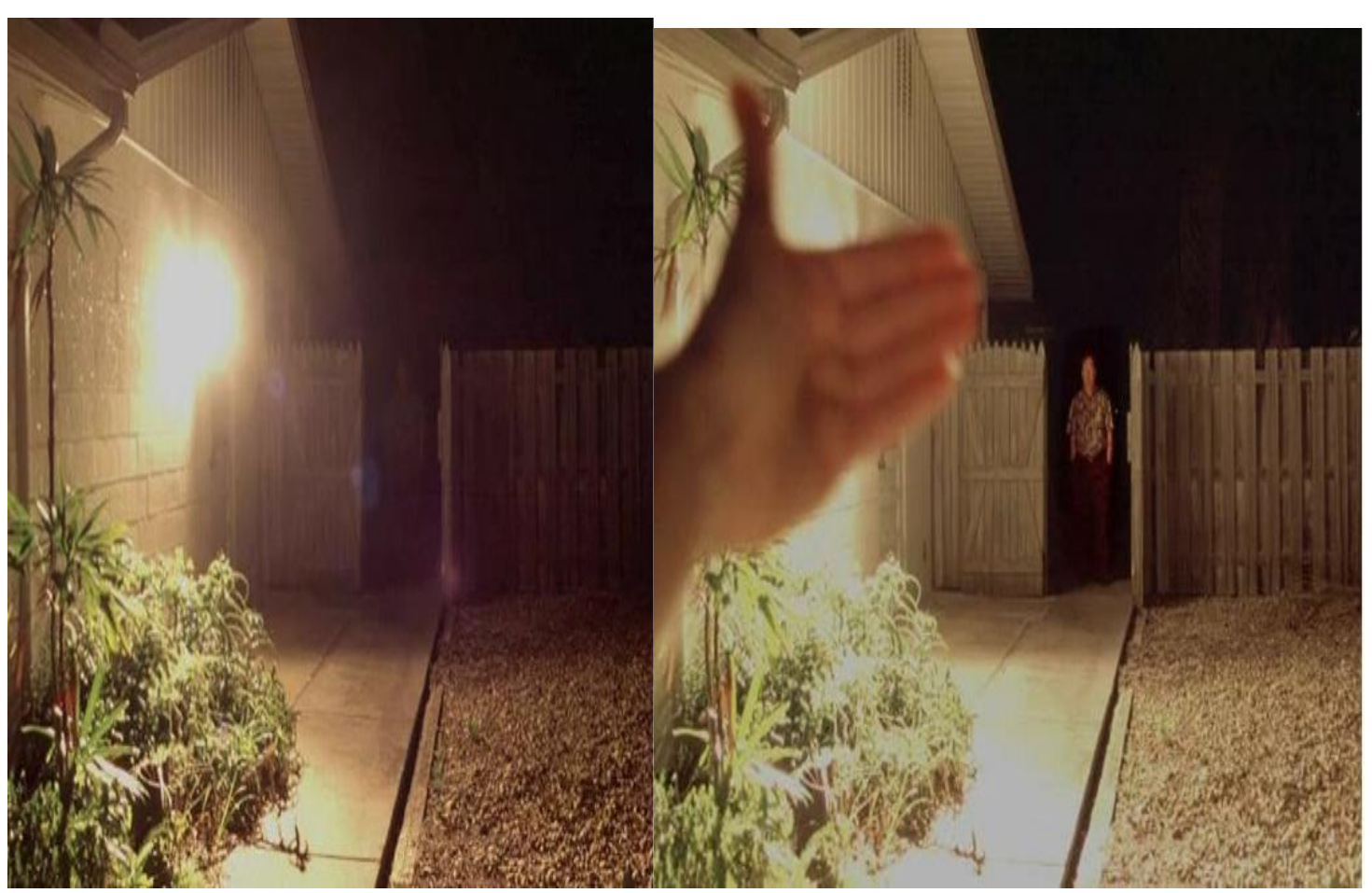

Fonte: http://www.lna.br/lp/definicao.html (acesso I8/Io/2018). Imagens: George Fleenor.

No que tange à área da economia, nos referimos ao que acontece nos 5.570 municípios do Estado brasileiro, isto com a colocação, principalmente da iluminação pública, que abarca formas errôneas, advindos de projetos mal elaborados no que se refere ao amparo da fonte de luz, bem como, da própria fonte de luz. No ano de 2020 foi consumido pelos 5.570 municípios em termos gerais e em média mês 39.518.458 MWh, com 85.773.993 consumidores, deste consumo destacamos a energia que foi usada pelos entes públicos, conforme demonstrado no quadro abaixo: 


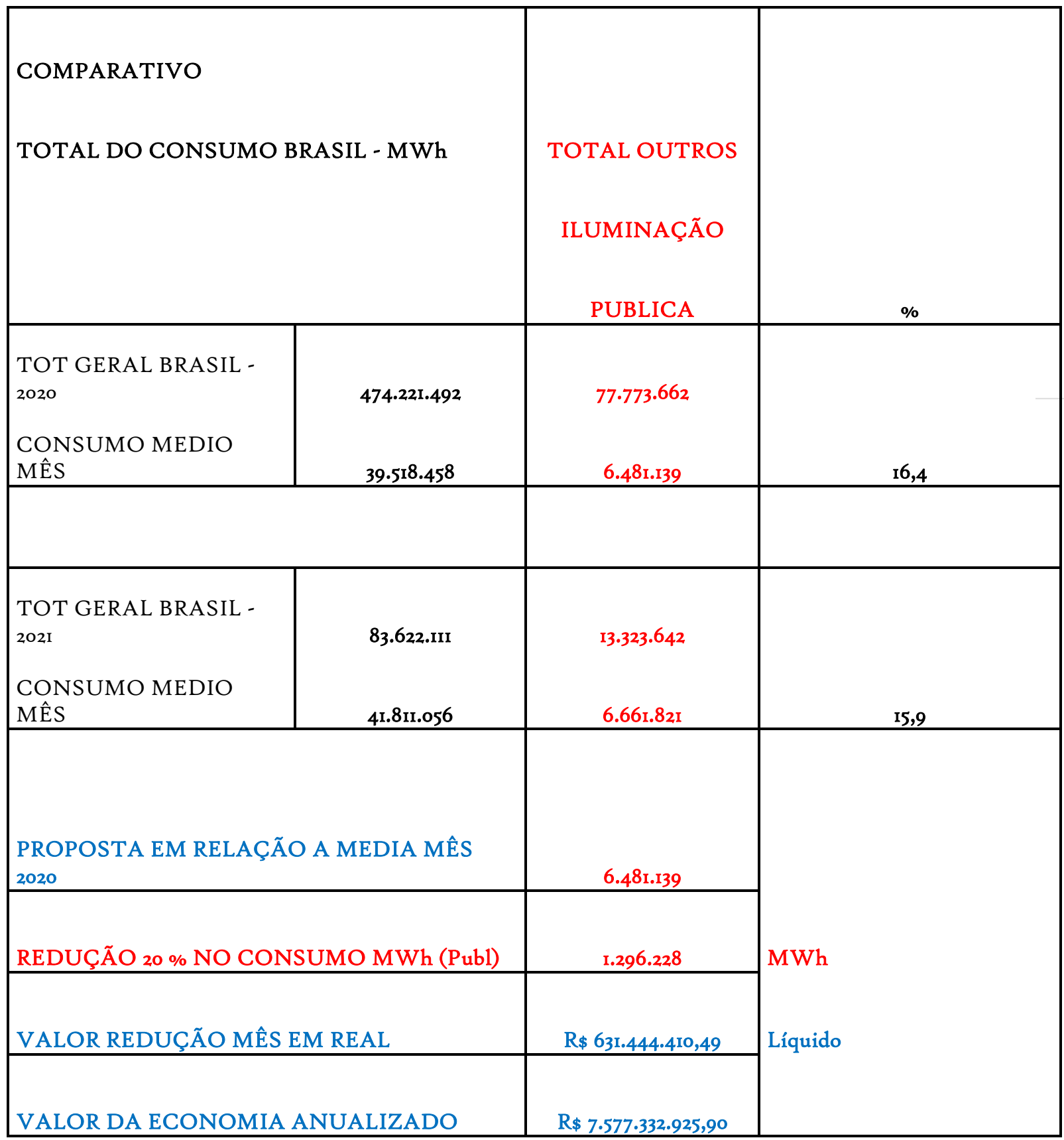

Nota-se que, dos 39.518.458 MWH em média/mês o consumo público foi de 6.481.139 MWH, deste número considera-se um desperdício médio em torno de $20 \%$ (vinte por cento), o que equivale a uma economia aproximada e anualizada da ordem de $\mathrm{R} \$ 7,5$ bilhões de reais ao valor do $\mathrm{MWH}$ de 2017, que não sofreu atualização até os 
dias de hoje. O que se propõe é mudança no que fazemos de inadequado hoje para termos um futuro melhor. Conforme nos ilustra a figura 7 .

\section{Figura 7}

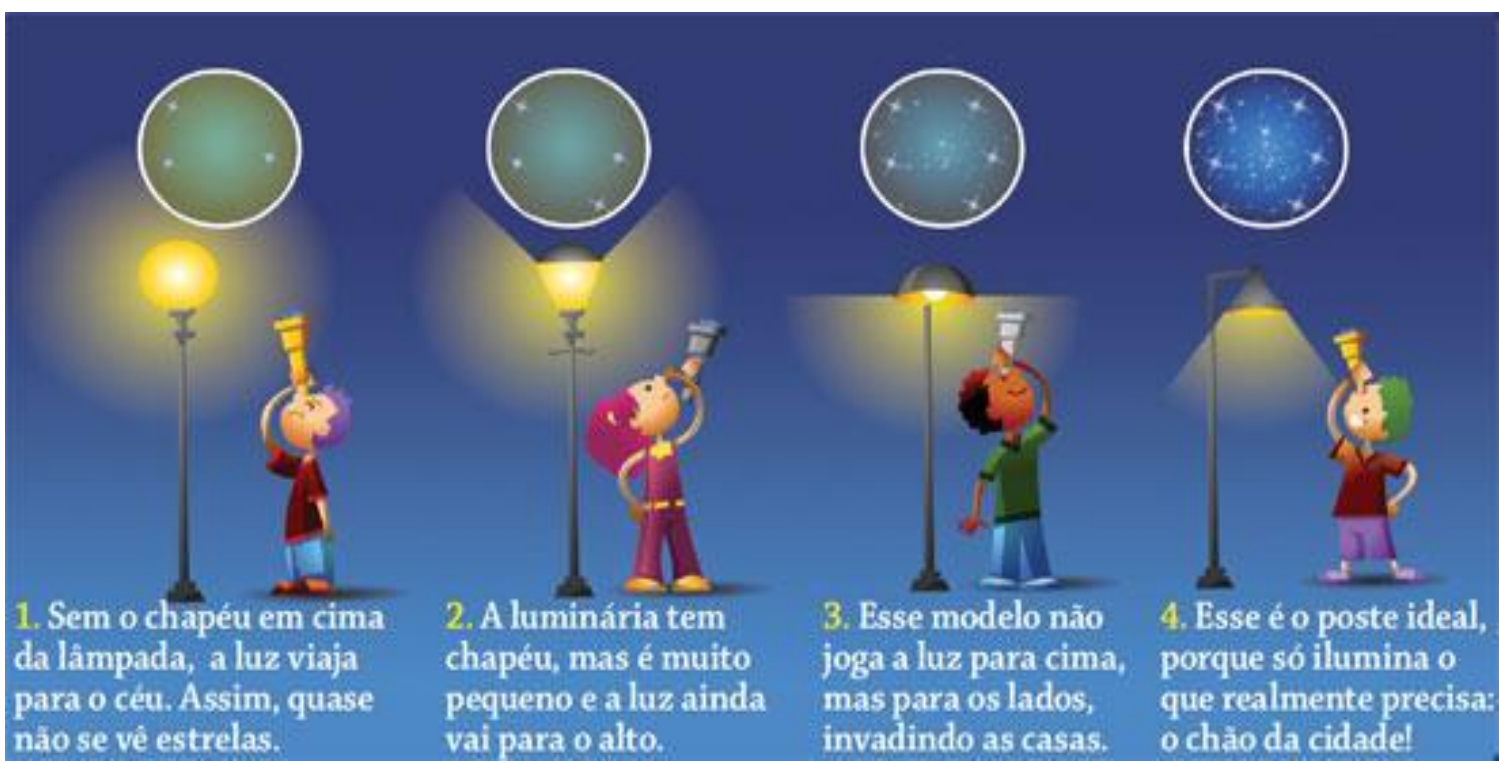

Fonte: http://www.lna.br/lp/referencias.html (acesso 18/10/2018).

No que concerne à área da educação, nos referimos, principalmente ao problema causado pela poluição luminosa à astronomia. Como é sabido, o astrônomo trabalha em suas pesquisas de objetos celestes, com captação de luz, esta advinda daqueles objetos. Notou-se que, toda luz mal colocada no meio ambiente, provenientes de grandes condomínios, casas e iluminação pública iluminam o céu, como se provou durante nossos estudos, isto vem a prejudicar os resultados das observações dos astrônomos pesquisadores. Além do que, impede qualquer pessoa de observar o céu, um patrimônio da humanidade e fonte do saber de nossa história. Notem as figuras 8 e 9, elas nos ilustram a cidade do Rio de Janeiro com iluminação excessiva e em direção ao céu e o que seria o ideal para a área da astronomia. Com pouco esforço você consegue vislumbrar a via láctea, objeto que se tornou difícil de visualização devido à poluição luminosa. 
Figura 8

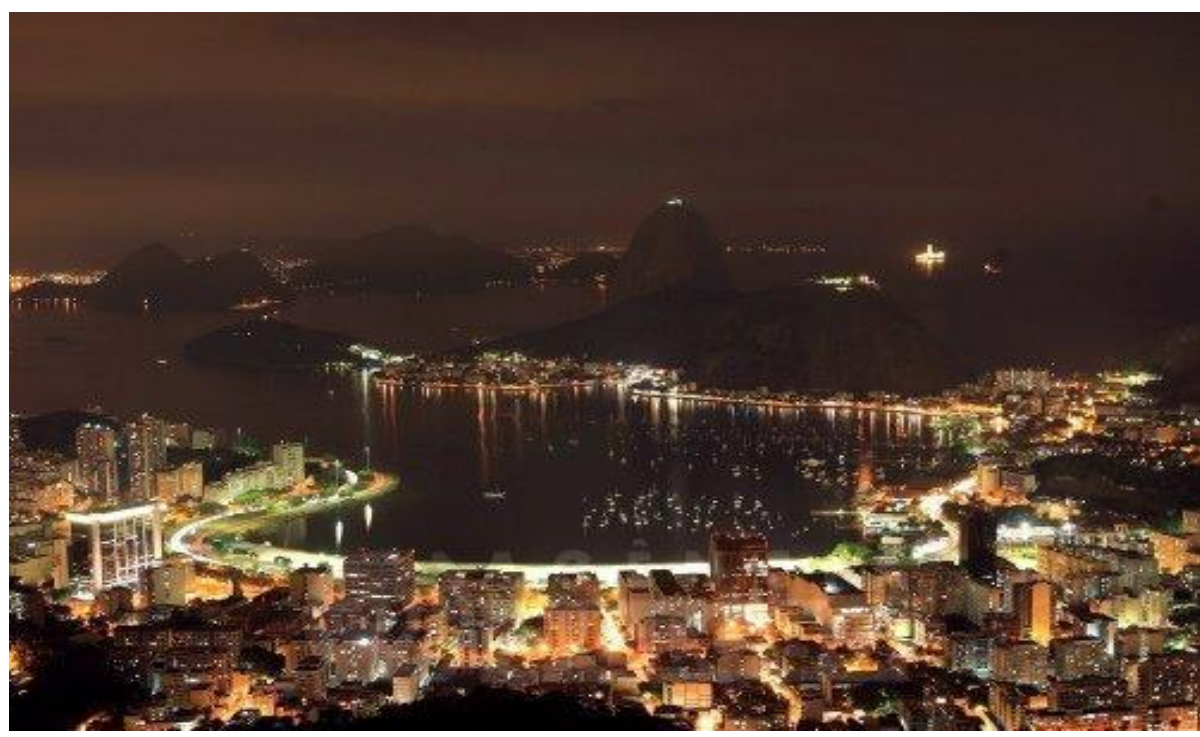

Fonte: https://unidospelaastronomia.wordpress.com/2015/o8/19/o-que-e-a-poluicao-luminosa-eporque-ela-e-tao-ruim-para-a-astronomia/ (acesso I8/10/2018)

Figura 9

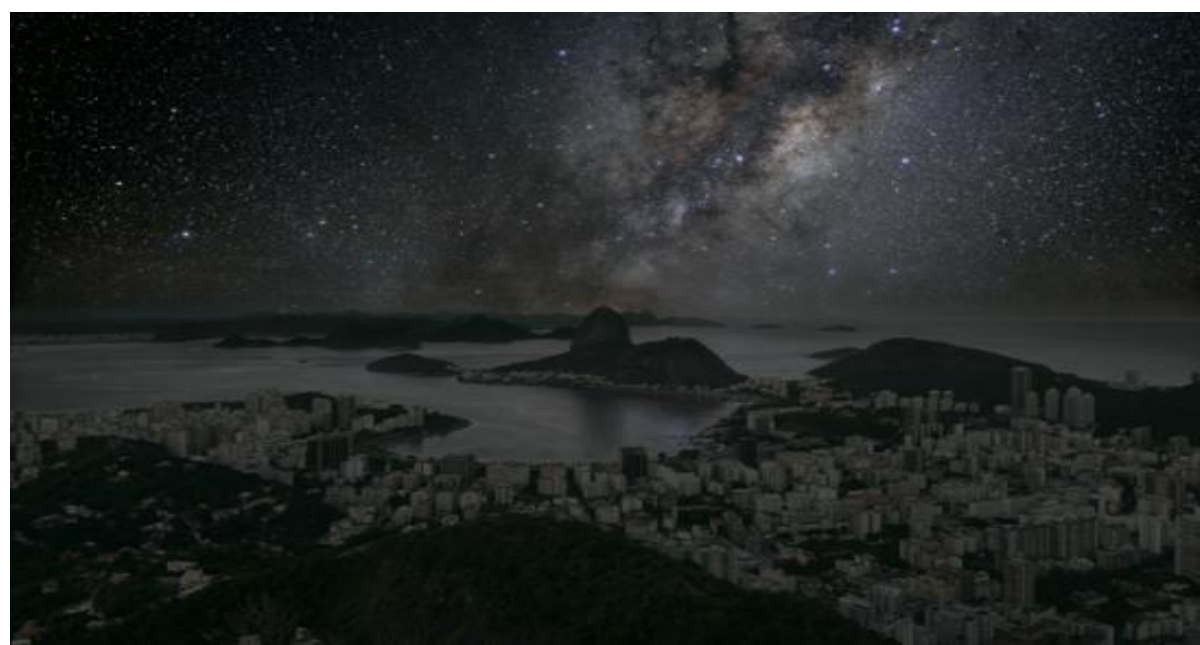

Fonte: https://unidospelaastronomia.wordpress.com/2015/o8/19/o-que-e-a-poluicao-luminosa-eporque-ela-e-tao-ruim-para-a-astronomia/ (acesso $18 / 10 / 2018$ ).

\section{MEIOS PROPOSTOS PARA MELHORIA}

O meio proposto para mudar esse quadro completamente confuso em termos de danos causados pela poluição luminosa é a educação. E isto, por meio de um processo de mudança - Figura ıo, que pode ocorrer segundo três aspectos inerentes 
aos seres humanos, ou seja, conhecimento; (saber ou não saber), atitude; (gostar ou não gostar) e comportamento; (fazer ou não fazer) e, administrado por dois métodos; participativo e impositivo, ou na melhor das hipóteses, uma combinação dos dois métodos. $\mathrm{O}$ método impositivo ocorre ou incide no comportamento, ou seja, a partir de amanhã faça-se de uma nova maneira, o que você fazia de outro modo. Esse método não leva em consideração o conhecimento e nem a atitude das pessoas. $O$ resultado obtido dele é rápido, mas não perdurará se não houver acompanhamento ou fiscalização constante. O exemplo típico desse método é a aplicação de uma nova lei.

Por outro lado, a mudança pode ocorrer pelo método participativo, ou seja, por meio de um processo educacional que se inicia por aumentar o grau de conhecimento do indivíduo, tornando-o sabedor do assunto em questão, assim esse indivíduo passa a gostar do que aprendeu e passa a fazer de uma nova maneira. Esse método é mais demorado e requer mais esforço em sua complementação, todavia perdurará, pois, um indivíduo mudado passa a ser um multiplicador de conceitos. Em nosso trabalho concluímos que será preciso uma combinação dos dois métodos para se obter resultados na redução da poluição luminosa, ou seja, propomos a aprovação de uma legislação específica para combater a poluição luminosa em nível nacional, em paralelo com um processo educacional, quiçá um portal combinado com material didático conceitual acerca de poluição em geral.

Figura 10

PROCESSO DE MUDANÇA

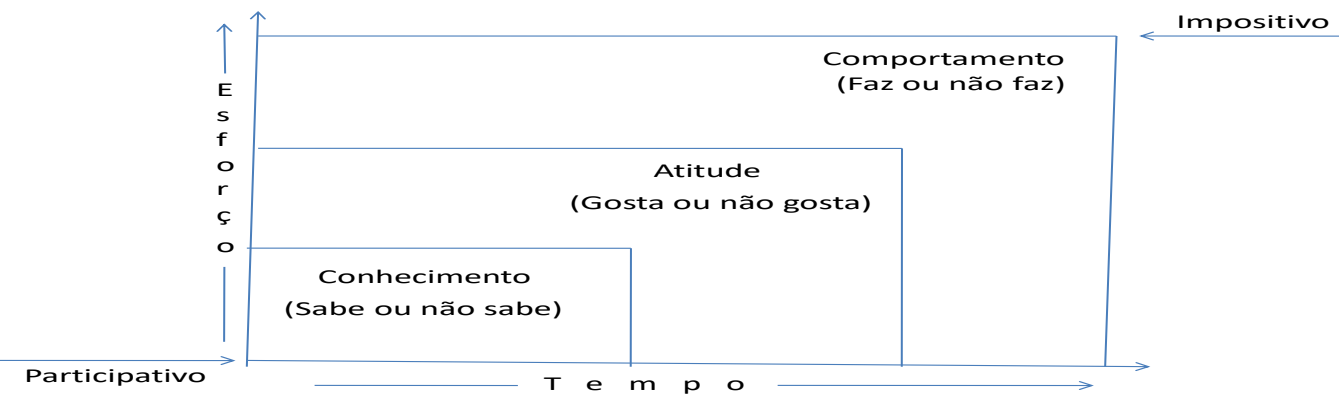

Fonte: Criação própria 


\section{DAS LEGISLAÇÕES EXISTENTES}

Percebemos que no Brasil não existe uma legislação abrangente que combata os efeitos malignos advindos da poluição luminosa, somente duas legislações foram localizadas, uma no município de Campinas que protege o entorno do observatório astronômico e outra no município de Caetés, no Estado de Minas Gerais e que está em desuso. Mas em países estrangeiros, tais como Chile, Itália, França, Tchecoslováquia, Iugoslávia, Portugal, Espanha, Estados Unidos já se combate a poluição luminosa a um longo tempo. Em alguns desses países o combate à poluição luminosa é feito simultaneamente por duas vias; uma via é a legislação e a outra são por meio de programas educacionais, aplicado aos estudantes. Essa estratégia apresenta melhor resultado porque o processo de mudança não ocorre apenas pelo modo impositivo e sim pelo participativo, informando e envolvendo sociedade, com o intuito de mudar o comportamento e a atitude das pessoas, conscientizando-as sobre os malefícios da poluição luminosa. O que se busca com esse artigo é conscientizar a sociedade para os perigos da poluição luminosa e a promulgação de uma lei que proteja o ecossistema daqueles malefícios.

\section{CONCLUSÃO}

Neste artigo, apresentamos inicialmente os tipos de poluição conhecidas e que afetam o meio ambiente em geral e causam danos aos seres humanos, à fauna, à flora, à segurança; no ir e vir das pessoas, à economia dos 5.570 municípios brasileiros, isso em relação ao consumo e desperdícios de energia elétrica e a área da educação, no que tange à sua área da astronomia. Apontamos os principais malefícios causados pelas poluições em geral, inclusive afirmamos a posição combativa do Estado em termos de legislação aplicável a cada tipo de poluição. Entretanto, o trabalho de pesquisa a que nos propusemos fazer em nosso projeto tinha o condão de identificar, qualificar e quantificar os problemas causados pela poluição luminosa ao meio ambiente, bem como, entender a postura do Estado e sociedade organizada em relação ao combate a esse tipo de poluição, cujos malefícios são inegáveis. Ressaltamos ao longo do texto 
os malefícios causados pelos diversos tipos de poluição luminosa, e mostramos como elas afetam as áreas dos direitos humanos, da economia, da segurança e, em particular, à área da Astronomia, nos campos profissional, amador, educacional e cultural. Quanto a uma legislação que combata a poluição luminosa, nos foi possível perceber que no Brasil não existe uma legislação abrangente que combata os efeitos malignos advindos da poluição luminosa, o que é diferente em alguns países estrangeiros, tais como Chile, Itália, França, Tchecoslováquia, Iugoslávia, Portugal, Espanha, Estados Unidos, onde já se combate a poluição luminosa a um longo tempo. Em alguns desses países o combate à poluição luminosa é feito simultaneamente por duas vias; uma via é a legislação e a outra é um programa educacional, aplicado aos estudantes. Essa estratégia apresenta melhor resultado porque o processo de mudança não ocorre apenas pelo modo impositivo e sim pelo participativo, informando e envolvendo a sociedade, com o intuito de mudar o comportamento e a atitude das pessoas conscientizando-as sobre os malefícios da poluição luminosa. Nesse sentido, nosso trabalho é abrangente, pois leva em consideração o aspecto legal, propondo um projeto de lei que assegura maior controle dos malefícios causados pela da poluição luminosa, bem como o aspecto educacional, sugerindo um trabalho em sala de aula, a partir da participação dos professores em conscientizar seus alunos. Com esse trabalho esperamos preparar nossos alunos para serem os multiplicadores dessa nova consciência no combate à poluição luminosa.

\section{REFERÊNCIAS BIBLIOGRAFICAS}

BADDILAY, C.Blinded by the light? British Astronomical Association, campaign for dark skies (CFDS), 2009. (Disponível em www.britastro.org/dark-skies).

CHUI, J. C.Y. Perception of light pollution in Hong Kong - An Empirical Study, Thesis to University of Hong Kong, 2009. (Disponível em http://hub.hku.hk/handle/I0722/52598) ou (http://dx.doi.org/ro.5353/th_b4098792) Acesso em 29/03/2016. 
THE ROYAL COMMISSION ON ENVIRONMENT POLLUTION. Artificial light in the environment, 2009.

(https://www.gov.uk/government/uploads/system/uploads/attachment_data/file/ 228832/9780108508547.pdf.pdf). Acesso em 02/o4/2016.

VALLE, C. E. Qualidade ambiental. ISO ı400o. $5^{\circ}$ ed. São Paulo: SENAC, 2004.

MIZON, B. Light pollution - responses and remedies. $\mathrm{I}^{\underline{\mathrm{a}}}$ edition - $2^{\underline{\mathrm{a}}}$ edition, Editora Springer, London, $2002-2012$. 